\title{
AN ANALYTICAL SOLUTION OF KINEMATIC WAVE EQUATIONS FOR OVERLAND FLOW UNDER GREEN-AMPT INFILTRATION
}

\author{
Giorgio Baiamonte, Carmelo Agnese
}

\section{Introduction}

In the past many efforts were made to advance the knowledge of the hydrologic response at the hillslope scale. Horton [1933, 1938] was one of the first proponents of the concept of the infiltration excess mechanism for which overland flow occurs. Particularly, Horton's mechanism is the main mechanism of runoff production in arid and semi-arid regions, generally characterised by high rainfall intensity and by hillslopes with poor vegetation cover; in this case runoff occurs when the rainfall intensity exceeds the soil infiltration capacity. Agnese [2001, 2007] founds an analytical solution for the non linear storage model of hillslope response, valid for all flow regimes; the proposed solution is initially developed for simple planar slopes and then extended to hillslopes of complex topography. Agnese [2006] combined the analytical solution of the overland flow equation with the Green [1911] infiltration model to derive the response on an infiltrating hillslope.

The non- linearity of the hillslope response has also been described by the kinematic wave approximation of the De Saint-Venant equations [1871]. Firstly, Lighthill [1955] gave the theoretical background of kinematic waves, which has since been a subject of much discussion in hydrologic literature and has been applied to a multitude of environmental and water resource problems. Henderson [1964], and Woolhiser [1967], developed an analytical solution for the kinematic wave model. Cundy [1985] and Luce [1992] derived an analytical solution of the kinematic wave equations when the infiltration rate is described by the Philip two-terms formula. Mizumura [2006], by approximating Manning's formula by a polynomial of second order, found an analytical solution of the kine-

Paper received 23.07.2009; accepted 10.03.2010

Prof. Ing. Giorgio Baiamonte, Associate Professor, Dipartimento I.T.A.F., Università di Palermo, Viale delle Scienze 4 - 90128 Palermo, Italy E-mail: giorgio.baiamonte@ unipa.it

Prof. Ing. CARMelo Agnese, Full Professor, Dipartimento I.T.A.F., Università di Palermo matic wave model for time-varying excess rainfall of sinusoidal functions. Giráldez [1996] analytically integrated kinematic wave equations in the case in which the infiltration process is described by the model of Smith [1978]. Woolhiser [1996] studied the effect of spatial variability of saturated hydraulic conductivity on hortonian overland flow. Also this paper focuses on an analytical solution of the kinematic wave model which, despite being limited to special cases, is very successful on understanding the dynamics of the hillslope response; this item is also asserted by Giráldez [1996], which highlighted that the usefulness of analytical solution helps the insight of the problem prior to the application of time-consuming numerical methods. Following the same approach suggested by Giráldez [1996], in this work the analytical solution of the kinematic wave model with the Green [1911] infiltration, is derived; the solution is valid for the transitional flow regime, intermediate between laminar and turbulent regime. A transitional regime can be considered a reliable flow condition when, to the laminar overland flow, is also associated the effect of the additional resistance due to the raindrop impact (disturbed laminar flow, Brutsaert, 1972).

\section{Green-Ampt infiltration model}

The incoming of the Hortonian runoff is related to the evidence of free water on soil surface, and thus to the presence of a thin saturated soil layer; this implies that the rainfall intensity has to be greater than the infiltration rate capacity. According to the Green and Ampt model, under the simplifying hypotheses of constant rainfall intensity, one-dimensional infiltration in a homogenous, non hysteretic and non swelling soil, lacking of macropores, with constant initial water content along the soil profile, the time to ponding, $t_{p}$, is given by [Smith 2002]:

$$
t_{p}=\frac{t_{c} K_{s}^{2}}{i\left(i-K_{s}\right)}
$$

where $K_{s}$ is the saturated hydraulic conductivity and $t_{c}$ 
is a characteristic time-scale of the infiltration process, called the sorptivity time scale. $t_{c}$ is associated to the macroscopic capillary length, $\lambda_{c}$, as:

$$
t_{c}=\frac{\left(\theta_{s}-\theta_{i}\right) K_{s}}{K_{s}-K_{i}}
$$

where $\theta$ is the volumetric water content, $K$ is the hydraulic water conductivity, and the subscripts, $s$ e $i$, are referred to the saturated and initial condition, respectively [White 1987].

The infiltration rate $f$, according to the Green and Ampt model, is given by:

$$
t-t_{p}=t_{c}\left(\frac{K_{s}}{\left(f-K_{s}\right)}-\frac{K_{s}}{\left(i-K_{s}\right)}+\Psi\right)
$$

where the dimensionless function $\Psi$ has the following expression:

$$
\psi=\ln \left(\frac{i\left(f-K_{s}\right)}{f\left(i-K_{s}\right)}\right)
$$

The cumulative depth of rainfall excess at any instant $t, R(t)$, is defined as:

$$
R(t)=\int_{i_{r}}^{t} r(t) d t=\int_{i,}^{t}(i-f(t)) d t
$$

where $r(t)=i-f(t)$ is the instantaneous rainfall excess. By using a simple change of variable, eq. (5) can be written:

$$
R(i)-(i-f)\left(\left(-t_{p}\right)-\int_{f}^{t}\left(\left(-t_{p}\right) d f\right.\right.
$$

By substituting (3) in (6) and by integrating:

$$
R(f)-t_{c}\left(\frac{i-f}{f-K_{s}} K_{s}+i \psi\right)
$$

Eq. (7) let to determine the temporal variation of rainfall excess, very useful for hydrologic applications:

$$
\frac{r(t)}{i}=1-\rho^{-1}-\left(\rho t / t_{c}+1-\rho \ln \frac{\rho(1-n)-1}{(\rho-1)(1-n)}\right)^{-1}
$$

where $\rho=i / K_{s}$ is the ratio between rainfall intensity and saturated hydraulic conductivity. Eq. (8) agrees with that one differently derived by Agnese [2006].

\section{Kinematic wave equations}

Lets consider a plane hillslope, in which the flow is rigorously downslope (Fig. 1).

It is known that kinematic wave equations can be derived by the so-called shallow water equations [Brutsaert 2005], expressing the conservation of mass and momentum, respectively:

$$
\frac{\partial h}{\partial t}+L \frac{\partial q}{\partial x}=(i-f)
$$

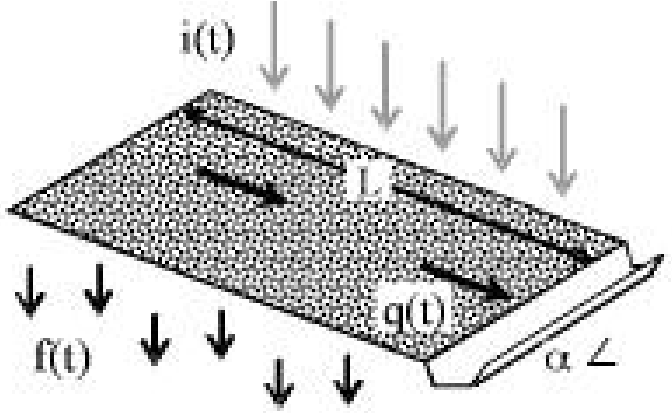

Fig. 1 - Sketch of the hillslope.

$$
\frac{\partial u}{\partial t}+u \frac{\partial u}{\partial x}+g \frac{\partial h}{\partial x}-g\left(S_{0}-S_{f}\right)-\frac{u}{h}(i-f)
$$

where $h$ is the mean depth of flow, $t$ is the time, $L$ is the hillslope length, $q$ is the unit area discharge, $x$ is the downslope distance from the top of the hillslope, $u$ is the flow velocity, $g$ is the acceleration due to gravity, $S_{0}$ is bed slope, $S_{f}$ is friction slope. Under the assumption that the inertia and diffusion effects are negligible with respect to that of gravity and of friction, the momentum conservation equation (10) simply reduces to $S_{f}=S_{0}$. Physically, this equivalence states that the friction slope is assumed to be equal to the bed slope; therefore, by using the same notation of Agnese [2001], the Manning equation can be written as a function of $S_{0}$ :

$$
q=k \cdot h^{m}
$$

where $m$ accounts for the flow regime ( $m$ is usually taken to be equal to $5 / 3$ for turbulent flow, to 2 for transitional flow and to 3 for laminar flow) and $k_{*}$ parameter, describing hillslope "geometry" (length, slope and roughness), has the following expression:

$$
k=\frac{\sqrt{S_{0}}}{n L}
$$

where $n$ is the Manning friction factor.

By assuming the common initial and boundary conditions of null water depth:

$$
h(0, t)=h(x, 0)=0
$$

eqs. (9) and (11) lead to:

$$
\frac{\partial h}{\partial t}+m k \cdot L h^{m-1} \frac{\partial h}{\partial x}=(i-f)
$$

Equation (14), which describes the kinematic wave approximation, can be solved by the method of characteristics [Courant 1962], which converts the (14) to a pair of ordinary differential equations, expressing the time variation of water depth:

$$
\frac{d h}{d t}=r(t)-i-f(t)
$$

and the characteristic curve: 


$$
\frac{d x}{d t}=L \frac{d q}{d h}=m k \cdot L h^{m-1}=m u
$$

The unique relationship between $q$ and $h$, expressed by (11), together with (15) and (16) allows to state that an imaginary observer moving in $x$ - $t$ plane at a speed equal to the kinematic wave celerity would see the flow rate increases at a rate equal to the lateral inflow $(i-f)$.

In the simplest case that overland flow occurs on an impervious hillslope, so that lateral inflow rate is equal to the rainfall intensity, the relationship for the time to equilibrium, $t_{e q}$, (i.e. the time that the observer, starting from the top of the hillslope, requires to achieve the bottom of the hillslope) is available. By integrating (16) along the hillslope from 0 to $L$, according to the notation we used, is:

$$
t_{e q}=k_{s}^{-1 / m} i(1-m) / m
$$

For the impervious hillslope, if the duration of rainfall, $t_{r}$, is greater than $t_{e q}$, a hydrograph for the kinematic wave model $(\mathrm{KW})$, can be obtained:

$$
\begin{aligned}
& q=k *(i t)^{w} \quad \text { if } t \leq t_{\text {eq }} \\
& q=i \quad \text { if } t_{\phi q}<t<t_{r} \\
& \left.q=i-m k t^{1 / m} i q^{(m-1)}\right) / m\left(r-t_{r}\right) \text { if } \quad t>t_{r}
\end{aligned}
$$

Fig. 2 highlights a good agreement between the normalised hydrograph derived by KW (eqs. 18), with the experimental measurements of Izzard [1944] carried out on an impervious plane covered with turf, for several experimental combinations, namely rainfall intensities $i=91.4$ and $45.7 \mathrm{~mm} \mathrm{~h}^{-1}$, slopes $S_{0}=0.01$, $0.02,0.04$ and plane lengths $L=22,15,7.3$ and 3.7 $\mathrm{m}$, in the case of a turbulent flow regime $(m=5 / 3)$. In the same figure the hydrograph derived by the nonlinear storage model (SM), according to the solution obtained by Agnese [2001], is also represented. As it can be observed, the SM model does not really pro-

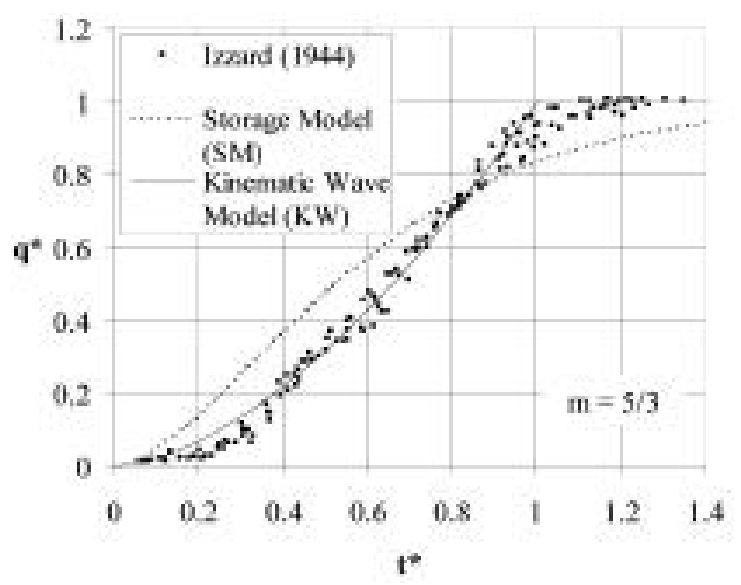

Fig. 2 - Comparison between the kinematic wave model (KW) and the non-linear storage model (SM) with the experimental measurements of Izzard [1944]. $\mathrm{q}^{*}$ is the discharge q normalized with respect to $\mathrm{i}$, and $\mathrm{t}^{*}$ is the time $\mathrm{t}$ normalised respect to $\mathrm{t}_{\mathrm{eq}}$. (modified from Brutsaert, 2005, pag. 205). duce a good fitting of Izzard's experimental overland flow measurements, therefore the SM model does not provide a close approximation to the exact solution. However, the SM model has an intrinsic diffusion capability compared to the KW model [Ponce 1997]. Therefore, the SM model should perform better in environmental conditions different from those investigated by Izzard, for which the effect of water storage on the hillslope could be so relevant to determine a slower hydrologic response.

Conversely to the KW model (eq.17), the equilibrium condition for the SM model can not be rigorously attained in a finite time. Notwithstanding, the Authors defined a time to equilibrium as the time necessary so that $q$ attains a value very close to $i(q=\alpha i$; with $\alpha$ close to 1 ):

$$
t_{e q}^{(S M)}=\frac{m}{m+1} k_{*}-\frac{1}{m_{i}} \frac{1-m}{m} \sum_{j=0}^{\infty} \frac{\alpha^{\frac{1+m j}{m}}}{1+m j}
$$

It is interesting to observe that eqs. (17) and (19) are equivalent for a particular value of $\alpha, \alpha_{*}$, that slightly depends on the flow regime:

$$
\frac{m}{m+1} \sum_{j=0}^{\infty} \frac{\alpha_{s}^{1+\infty} \frac{\alpha_{j}}{1+m j}}{\alpha_{j}}=1
$$

For $m=5 / 3,2$ and $3, \alpha_{*}$ results equal to $0.83,0.82$ and 0.8 respectively.

\section{Water depth and characteristics in the different integration domains}

The characteristic curves may be grouped in several domains, recognisable in a $x$ - $t$ plane, depending on their origin: the distance axis at the time to ponding for the first domain, the part of the time axis from $t_{p}$ up to the duration of rain, $t_{r}$, for the second domain and the rest of $x$-t plane for the third domain (Tab. 1). In the following kinematic equations they will be integrated in these three domains [Giráldez 1996].

\begin{tabular}{l|l|l} 
& $x$ bound & $t$ bound \\
\hline I domain & $0<x<L$ & $t=t_{p}$ \\
II domain & $x=0$ & $t_{p}<t<t_{p}$ \\
III domain & $0<x<L$ & $t>t_{r}$ \\
\hline
\end{tabular}

TABLE 1 - Boundaries of the three domains.

\subsection{Domain 1: Characteristic originating at $\left(0<x<L, t=t_{p}\right)$}

For the first domain, at the time to ponding, characteristics, originating at any section distant $x_{0}$ from the top of the hillslope, are defined as:

$$
\int_{x_{1}}^{x} d x=m k \cdot L \int_{i_{p}}^{t} h^{m-1} d t=m k \cdot L \int_{0}^{h} \frac{h^{m-1}}{i-f} d h
$$


To integrate (21), one could change the variable $h$ with $f$. At this aim, since according to (15) $h=R$, by deriving (7) with respect to $f$, we obtain:

$$
d h=t_{c} K_{t}^{2} \frac{(f-i)}{f\left(f-K_{t}\right)^{2}} d f
$$

Then, by substituting (22) in (21) one can obtain:

$$
\int_{s_{s}}^{x} d x=-m k_{s} L t_{c} K_{s}^{2} \int_{f}^{r} \frac{h^{w-1}}{f\left(f-K_{s}\right)^{2}} d f
$$

in which $h$ is given by eq. 7 .

For $m=2$, the integral on the right-hand side leads to an analytical solution of the characteristic:

$$
\begin{aligned}
& \frac{x-x_{0}}{L}=\frac{f_{e}^{2} K_{*}}{\left(f-K_{s}\right)^{2}\left(i-K_{s}\right)} . \\
& {\left[\begin{array}{l}
(i-f)\left(f+i-2 K_{s}\right) K_{i}+ \\
i\left(i-K_{s}\right)\left(f-K_{s}\right) p\left(2 K_{s}+\left(f-K_{s}\right) w\right)
\end{array}\right]}
\end{aligned}
$$

where $\Psi$ is the function defined by (4). It could be observed that for the first domain, characteristics can be normalized respect to $t_{c}^{2} k_{*}$.

\subsection{Domain 2: Characteristic originating at $\left(x=0, t_{p}<t<t_{r}\right)$}

To analytically derive the characteristic curves of the second domain, originating at any time $t_{0}>t_{p}$, it is firstly necessary to express the water depth $h$ as a function of $t_{0}$ (through $f_{0}$ ):

$$
h=\int_{r_{0}}^{2}(i-f) d t=(i-f)\left(t-t_{0}\right)-\int_{f}^{f_{0}}\left(t-t_{0}\right) d f
$$

where $f_{0}$ is the infiltration capacity at the time $t_{0}$.

As an example, for $K_{s}=3.33 \mathrm{~mm} / \mathrm{h}$ and $t_{c}=0.1 \mathrm{~h}$, Figure 3 reports the infiltration capacity curve according to the Green Ampt model, where the pair $\left(t_{0} f_{0}\right)$ is indicated.

In order to integrate (25), one could modify eq. (3)

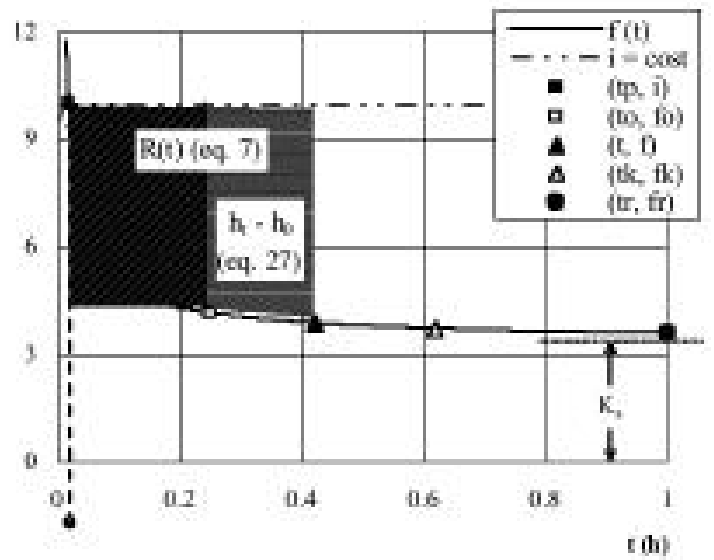

Fig. 3 - Infiltration capacity according to the Green Ampt model, for $\mathrm{K}_{\mathrm{s}}=3.33 \mathrm{~mm} / \mathrm{h}$ and $\mathrm{t}=0.1 \mathrm{~h}$. In the figure the same typical values of the infiltration capacity with the corresponding times, and cumulative depth of rainfall excesses, defined by eq. (7) and eq. (27) are also indicated. by replacing the pair $\left(t_{p}, i\right)$ with the pair $\left(t_{0}, f_{0}\right)$ :

$$
t-t_{0}=t_{c}\left(\frac{K_{z}}{\left(f-K_{s}\right)}-\frac{K_{z}}{\left(f_{0}-K_{s}\right)}+\Psi_{0}\right)
$$

obtaining:

$$
h=t_{c}\left(\frac{K_{s}\left(f_{0}-f\right)\left(i-K_{s}\right)}{\left(f-K_{s}\right)\left(f_{0}-K_{s}\right)}+i \psi_{0}\right)
$$

where $\Psi_{0}$ function is defined by:

$$
w_{0}=\ln \left(\frac{f_{0}\left(f-K_{s}\right)}{f\left(f_{0}-K_{s}\right)}\right)
$$

Eq. (27) could also be obtained by using twice eq (7) to evaluate the difference $h_{t}-h_{0}$ with $h_{t}$ and $h_{0}$ water depths corresponding to $f$ and $f_{0}$, respectively.

Finally, to derive characteristics, eq. (27) can be used for the integration of (16):

$$
\int_{0}^{\pi} d x=m k+L \int_{f_{s}}^{l} h^{m+1} d t
$$

Only for $m=2$, an analytical solution can be determined:

$$
\begin{aligned}
& \frac{x}{L}=\frac{f_{s}^{2} K_{0}}{\left(f-K_{s}\right)^{2}\left(f_{0}-K_{s}\right)^{2}} \cdot \\
& \left(\begin{array}{l}
\left(f_{0}-f\right) K_{s}^{2} \\
{\left[2 f f_{0}-f i+f_{0} l-\left(f+3 f_{0}\right) K_{x}+2 K_{s}^{2}\right]} \\
+2\left[f\left(f_{0}-i\right)+f_{0}\left(i-K_{s}\right)\right] \\
\left(f-K_{s}\right)\left(f_{0}-K_{s}\right) K_{s} w_{0} \\
+i\left(f-K_{s}\right)^{2}\left(f_{0}-K_{s}\right)^{2} \Psi_{0}^{2}
\end{array}\right)
\end{aligned}
$$

Also in this case, characteristics can be normalized respect to $t_{c}^{2} k_{*}$.

\subsection{Domain 3: Characteristic originating at the end of the rainfall up to zero water flow $\left(i=0, t>t_{r}\right)$}

For $t$ greater than the rainfall duration $t_{r}, i=0$ and the water depth decreases with time:

$$
\frac{d h}{d t}=-f
$$

Analogously to (25), eq. (31) can be rewritten by introducing the infiltration capacity at the end of the rainfall, $f_{r}$, and the water depth $h_{*}$ at any position $x_{*}$ for time $t_{r}$ :

$$
h-h_{*}-\int_{t_{0}}^{t}-f d t=-f\left(t-t_{r}\right)-\int_{f}^{f_{t}}\left(t-t_{0}\right) b f
$$

Thus, by replacing $t_{0}$ with $t_{r}$ in (26) and then substituting in (32), the integration yields:

$$
h-h_{t}=-K_{s}^{2} t_{c} \frac{\left(f_{r}-f\right)}{\left(f-K_{s}\right)\left(f_{r}-K_{s}\right)}
$$

which highlights the decreasing water depth from the end of the rainfall. By putting $h=0$ into (33), the value of infiltration capacity when water depth goes to zero, $f_{z w}$, can be determined: 


$$
f_{s w}=K_{s}\left(\frac{f_{f}\left(h_{s}+K_{s} t_{c}\right)-h_{s} K_{s}}{K_{s}\left(K_{s} t_{c}-h_{s}\right)+f_{p} h_{s}}\right)
$$

Analogously to the other domains, characteristic curves in the third domain are defined as:

$$
\int_{s=}^{x} d x=m k \cdot L \int_{I^{\prime}}^{t} h^{w-1} d t=m k \cdot L \int_{0}^{h} \frac{h^{w-1}}{-f} d h
$$

The differential of water depth can be obtained by putting $i=0$ into eq. (22):

$$
d h=\frac{t_{c} K_{s}^{2}}{\left(f-K_{s}\right)^{2}} d f
$$

By substituting eq. (36) in eq. (35), for $m=2$, an integrable form of the characteristics can be obtained:

$$
\int_{x_{s}}^{x} d x=-2 k+L \int_{f}^{f_{f}^{h}} \frac{t_{f} K_{s}^{2}}{\left.f-K_{s}\right)^{2}} d f
$$

which yields:

$$
\begin{aligned}
& \frac{x-x_{s}}{L}=\frac{k_{r} t_{c}}{\left(f-K_{s}\right)^{2}\left(f_{r}-K_{s}\right)^{2}} \\
& {\left[\begin{array}{l}
2 h_{r}\left(f-K_{s}\right)\left(f_{r}-K_{s}\right)+ \\
K_{s} t_{c}\left(2 f f_{r}-K_{s}\left(f+3 f_{r}\right)+2 K_{s}^{2}\right) \\
K_{s}(f r-f)+ \\
-2 \psi_{r}\left(f-K_{s}\right)^{2}\left(f_{r}-K_{s}\right) \\
{\left[h_{s} K_{r}-f_{r}\left(h_{s}+K_{s} t_{c}\right)\right]}
\end{array}\right]}
\end{aligned}
$$

where the dimensionless function $\Psi_{r}$ is defined as:

$$
\Psi_{r}=\ln \left(\frac{f_{r}\left(f-K_{s}\right)}{f\left(f_{r}-K_{r}\right)}\right)
$$

Contrary to domains 1 and 2, characteristics of the third domain can be normalized only respect to $k_{*}$ and not respect to $t_{c}$. By putting $h=0$ and $f=f_{z w}$ into Eq.(33) and by substituting into Eq. (38), the position $x_{z w}$ of the zero water depth normalised with respect to $L$ can be obtained:

$$
\begin{aligned}
& \frac{x_{z w}}{L}=\frac{x_{*}}{L}+\frac{k * K_{s} t_{c}^{2}}{\left(f_{r}-K_{s}\right)^{2}\left(f_{z w}-K_{s}\right)^{2}} \\
& {\left[\begin{array}{l}
2 \psi_{z w} f_{z w}\left(f_{r}-K_{s}\right)^{2} \\
\left(f_{z w}-K_{s}\right)+\left(f_{r}-f_{z w}\right) K_{s} \\
{\left[2 f_{r} f_{z w}-\left(f_{r}+3 f_{z w}\right) K_{s}+2 K_{s}^{2}\right.}
\end{array}\right]}
\end{aligned}
$$

where

\begin{tabular}{|c|c|c|c|}
\hline & Symbol & Unit & Value \\
\hline rain & $\begin{array}{l}t \\
t_{f}\end{array}$ & $\begin{array}{l}\mathrm{mm} / \mathrm{h} \\
\mathrm{h}\end{array}$ & $\begin{array}{l}10 \\
l\end{array}$ \\
\hline soil & $\begin{array}{l}K_{x} \\
t_{c}\end{array}$ & $\begin{array}{l}\mathrm{mm} / \mathrm{h} \\
\mathrm{h}\end{array}$ & $\begin{array}{l}3.33 \\
0.1\end{array}$ \\
\hline hillskjpe & $\begin{array}{l}L \\
\alpha \\
n \\
k .\end{array}$ & $\begin{array}{l}\mathrm{m} \\
\text { deg } \\
\mathrm{m}^{-1 / 3} \mathrm{~s} \\
\mathrm{~m}^{-2 / 5} \mathrm{~s}^{-2}\end{array}$ & $\begin{array}{l}40 \\
30 \\
0.125 \\
0.141 \\
\end{array}$ \\
\hline Time to ponding & $t_{p}$ & h & 0.017 \\
\hline 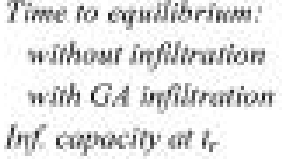 & $\begin{array}{l}t_{\text {cag }} \\
f_{k} \\
f_{r}\end{array}$ & $\begin{array}{l}\mathrm{h} \\
\mathrm{h} \\
\mathrm{mm} / \mathrm{h}\end{array}$ & $\begin{array}{l}0.44 \\
0.62 \\
3.6\end{array}$ \\
\hline
\end{tabular}

$$
\psi_{s w}-\ln \left(\frac{f_{r}\left(f_{r w}-K_{r}\right)}{f_{z w}\left(f_{r}-K_{r}\right)}\right)
$$

\section{Applications}

Towards the aim to compare the analytical solution of the kinematic wave here presented with the hillslope response derived by Agnese [2006], an application has been carried out for the same parameters used by the Authors (Tab. 2). The table also reports time to
TABLE 2 - Parameters used for the comparison between the kinematic wave model and the storage model by Agnese [2006].

ponding, $t_{p}$ (eq. 1), times to equilibrium without infiltration, $t_{e q}$ (eq. 17) and with a GA infiltration, $t_{k}$.

Fig. 4 shows some characteristics of the three domains.

Distance $x$ is normalized with respect to the length of the plane $L$; time $t$, shifted of time to ponding, is normalized with respect to the sorptivity time scale, $t_{c}$. The position $x_{z w}$ of the zero water depth (eq. 40) is also reported.

The rising limb of the hydrograph associated to the characteristic curves of Fig. 4, is shown in Fig. 5 and compared with that derived by Agnese and Baiamonte [2006], which used a non-linear storage model (SM) [Agnese 2001], for $m=2$, coupled too with the Green-Ampt infiltration model. The figure highlights that the SM hydrograph initially increases quicker than the KW hydrograph but a reverse behaviour successively occurs.

Because of the asymptotic behaviour of rainfall excess, also in the $\mathrm{KW}$ model a rigorous equilibrium condition cannot be defined; a characteristic equilibri-

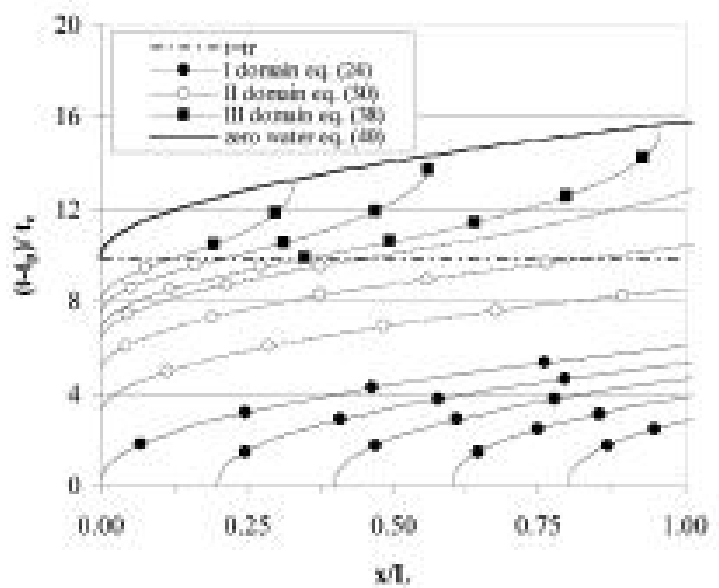

Fig. 4 - Characteristic curves in the three domains for parameters of Tab. II. Distance is normalised with respect to the length of the hillslope. Time is $t_{p}$ shifted and normalised with respect to the sorptivity time scale. Zero water depth and normalized rainfall duration are also shown. 


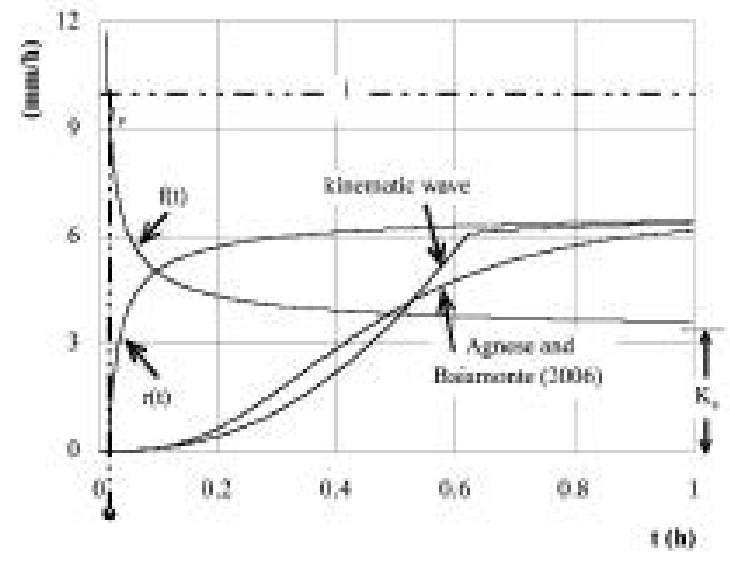

Fig. 5 - Comparison between the rising limb of the hydrograph computed following Agnese and Baiamonte [2006] with that obtained with the present solution. The figure also reports the corresponding infiltration capacity and rainfall excess curve.

um time can be defined as the time $t_{k}$, for which the characteristic, starting from the top of the hillslope, achieves the bottom of the hillslope.

By putting $x_{0}=0$ and $x / L=1$ into (24), the infiltration capacity $f_{k}$ associated to the time to equilibrium $t_{k}$ can be derived as:

$$
\begin{aligned}
& f_{k}=1-\frac{\left(i-K_{s}\right)\left(f_{k}-K_{s}\right)^{2}}{\left(f_{k}+i-2 K_{s}\right) K_{s}^{2}} \\
& \left(\frac{1}{k_{*} t_{c}^{2}}-i \psi_{k}\left(\frac{2 K_{s}}{\left(f_{i}-K_{s}\right)}+\psi_{k}\right)\right)
\end{aligned}
$$

where

$$
\psi_{k}=\ln \left(\frac{i\left(f_{k}-K_{s}\right)}{f_{k}\left(i-K_{s}\right)}\right)
$$

As expected, it could be shown that for $k_{*} \rightarrow 0$ characteristics never reaches the bottom of the hillslope and $f_{k}$ attains its limiting value $\left(K_{s}\right)$.

Once $f_{k}$ is known from eq. (42), time to equilibrium can be evaluated by putting $f=f_{k}$ into eq. (3). Figure 6 shows time to equilibrium $t_{k}$ vs $k_{*}$ with rainfall intensity as parameter, for $K_{s}=3.33 \mathrm{~mm} / \mathrm{h}$ and $t_{c}=0.1 \mathrm{~h}$.

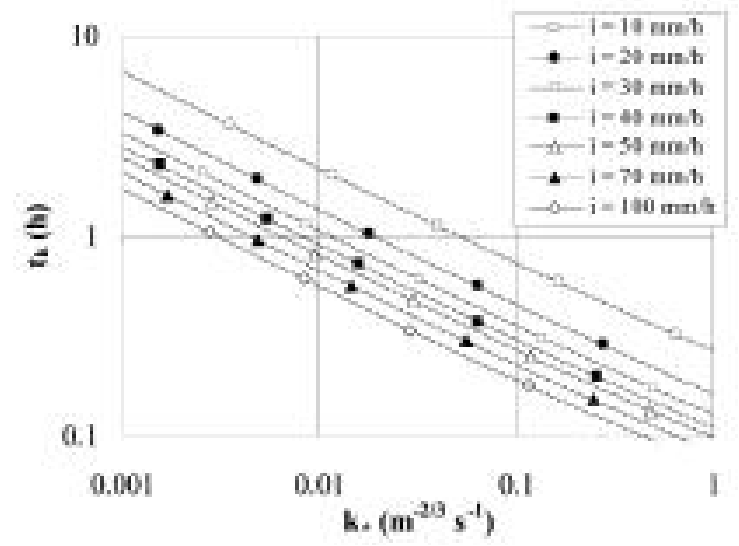

Fig. 6 - Time to equilibrium, $\mathrm{t}_{\mathrm{k}}$, versus hillslope geometry, $\mathrm{k}_{*}$ for the KW model, for different rainfall intensities.
As expected, for fixed rainfall intensity, $t_{k}$ decreases with increasing $k_{*}$ while for fixed $k_{*}, t_{k}$ decreases with increasing rainfall intensity.

To compare time to equilibrium $\mathrm{t}_{k}$ with time $t_{e q}$ corresponding to an impervious hillslope (eq. 17), Fig. 7 reports the ratio $t_{e q} / t_{k}$ vs. $k_{*}$, for different values of rainfall intensity.

The figure shows the effect of infiltration on the hillslope response: for any fixed hillslope geometry, with increasing rainfall intensity, the ratio $t_{e q} / t_{k}$ increases too. In fig. $8 \mathrm{a}$ and $8 \mathrm{~b}$, for parameters of Tab. II, the effect of rainfall intensity (fig. 8a) and of saturated hydraulic conductivity (fig. 8b) on the hydrograph, has been investigated.

As expected, the resulting hydrograph approaches to that corresponding to the impervious hillslope (eq. 18), with increasing rainfall intensity, or with decreasing saturated hydraulic conductivity. In the same figures, the discharge corresponding to the time to equilibrium, $q_{k}$, is also represented; interestingly, this relationship, obtained by using eqs. (7), (11) and (41), can be well-fitted by a power law function.

For the parameters reported in Tab. 2, Fig. 9 synthetically reports hydrographs normalized with respect to the asymptotic rainfall excess, $i-K_{s}$, for different values of the hillslope length $L(0.5<L<40 \mathrm{~m})$. It can be observed that response is quicker and quicker with decreasing $L$, at the first domain as well as at the third domain; while at the boundary between the $1^{\text {st }}$ and the $2^{\text {nd }}$ domain, the time to equilibrium, $t_{k}$, and the corresponding discharge, $q_{k}$, decreases with $L$.

By using eqs. (34), (38) and (40), the position, $x_{z w}$, at which zero water depth occurs, is also represented in Fig. 9. One can observe that time to zero water depth, $t_{z w}$, (no overland flow) increases with the length of the hillslope $L$.

\section{Conclusions}

This paper focuses on the analytical solution of the kinematic wave model coupled with the well-known

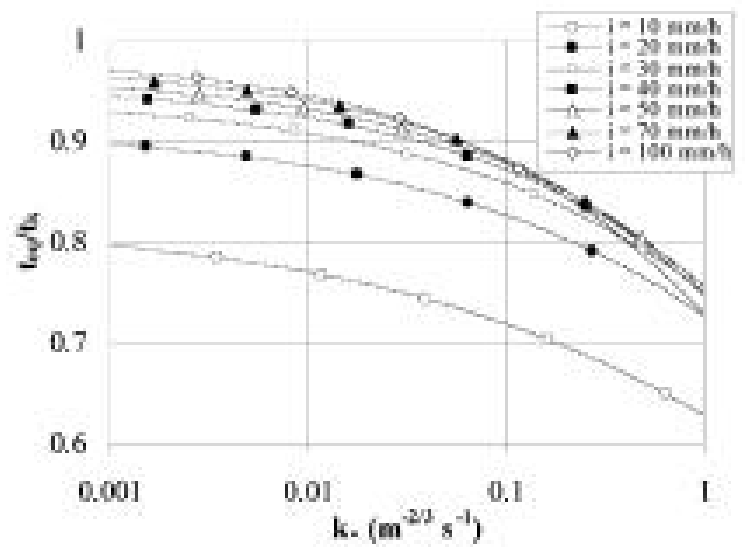

Fig. 7 - Ratio between time to equilibrium for the impervious hillslope and for the infiltrating hillslope, $\mathrm{t}_{\mathrm{eq}} / \mathrm{t}_{\mathrm{k}}$, versus hillslope geometry, for different rainfall intensities. 


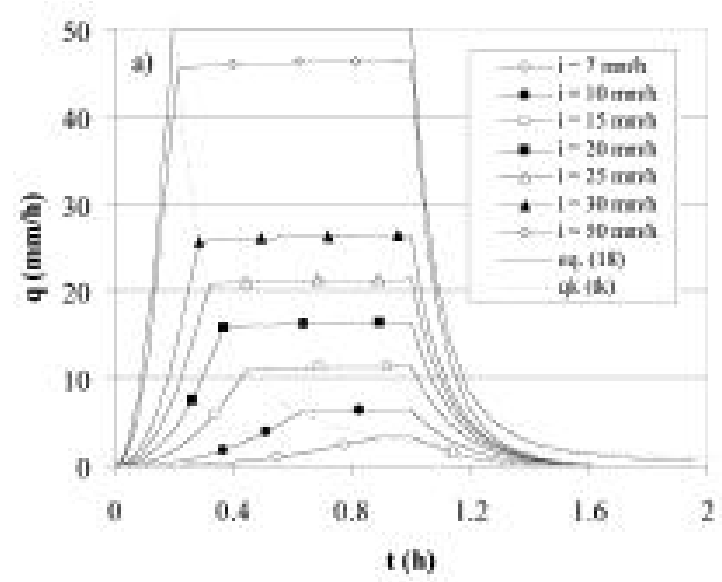

Fig. 8a- Hydrographs obtained with the present solution for different rainfall intensities. The figure also reports the hydrograph corresponding to an impervious hillslope (eq. 18) and the discharge-time to equilibrium relationship.

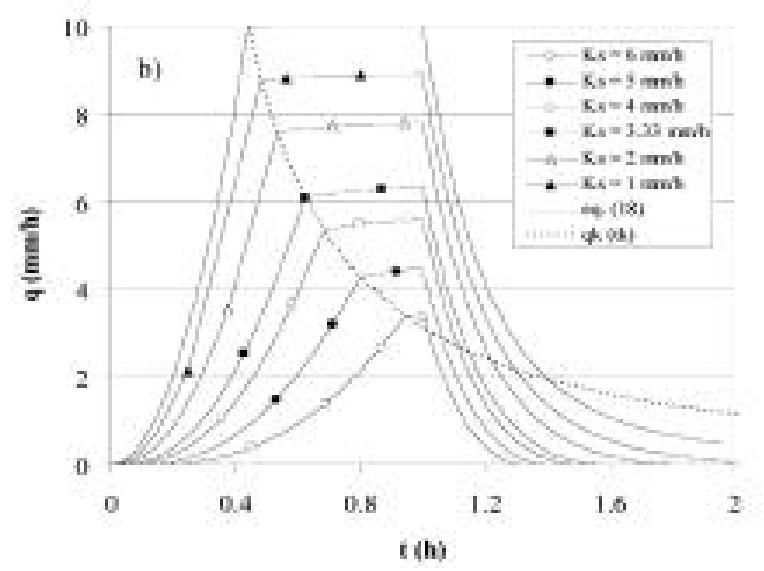

Fig. 8b- Hydrographs obtained with the present solution for different saturated hydraulic conductivity values. The figure also reports the hydrograph corresponding to an impervious hillslope (eq. 18) and the discharge-time to equilibrium relationship.

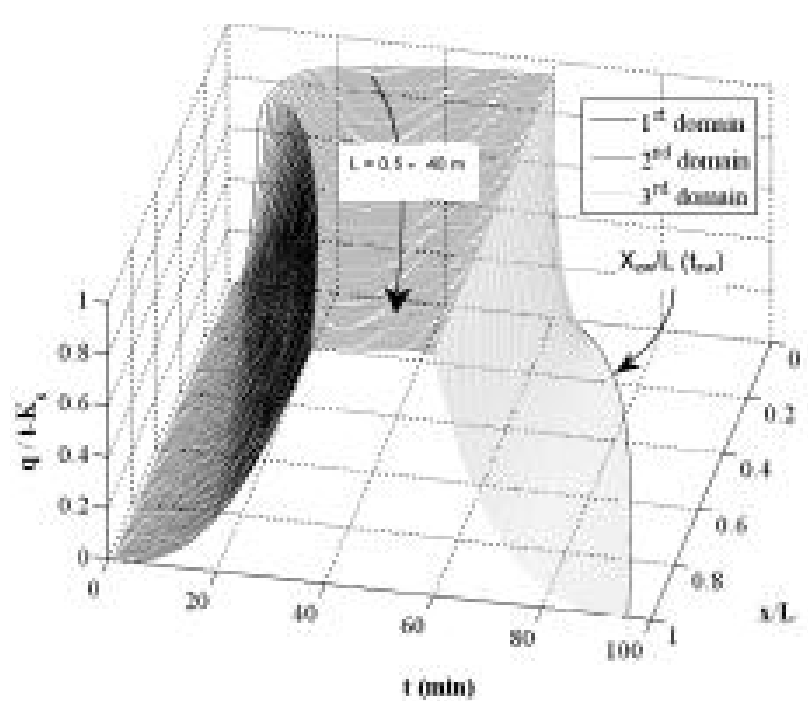

Fig. 9 - Hydrographs normalized with respect to the maximum rainfall excess value, $\mathrm{i}$ - Ks, obtained with the present solution, for different value of the length of the hillslope $\mathrm{L}(0.5<\mathrm{L}<40 \mathrm{~m})$. The relationship showing the position, $\mathrm{x}_{\mathrm{zw}}$, at which, for different $\mathrm{L}$ values, zero water depth occurs is also reported.
Green-Ampt infiltration model. The solution has been carried out, for the case of a transitional flow regime, following the same approach suggested by Giráldez [1996]. Characteristic equations, derived for each domain, depend on parameters related to rainfall, hillslope geometry, and soil. For one soil an application of the proposed solution useful to understand the dynamics of the hillslope response, was carried out. The effect of the rainfall intensity and the effect of the saturated hydraulic conductivity on the hillslope response was also investigated. The presented solution agrees, for the case of an impervious hillslope, with that originally derived by Woolhiser [1967].

\section{References}

Agnese C., Baiamonte G., Sulla risposta idrologica di un versante a prevalente deflusso hortoniano, Rivista di Ingegneria Agraria (2006), vol. 1, pp. 43-54 (in Italian).

Agnese C., Baiamonte G., Corrao C., A simple model of hillslope response for overland flow generation, Hydrol. Processes (2001), 15, 3225-3238.

Agnese C., Baiamonte G., Corrao C., Overland flow generation on hillslopes of complex topography: analytical solutions, Hydrol. Processes (2007), 21, 1308-1317.

Brutsaert W., Discussion of "Mechanics of sheet flow under simulated rainfall", J.Hydraul. Div. Proc. ASCE, 98 HY(2) (1972), 406-407.

Brutsaert W., Hydrology: An introduction, Cambridge, (2005).

Courant R., Hilbert D., Methods of Mathematical Physics, vol. 2, Wiley-Interscience (1962), New York.

Cundy T.W. and Tento S.W., Solution to the kinematic wave approach to overland flow routing with rainfall excess given by Philip's equation, Water. Resour. Res. (1985), 21, 1132-1140.

De Saint Venant B., Théorie du movement non-permanent des eaux avec application aux crues des revierés et al.'introduction des marées dans leur lit. Academie des Sciences [Paris] Comptes (1871), 73, 148-154, 237-240.

Foster G.R., Lane L.J., User requirements: USDA - Water Erosion Prediction Project (WEPP) (1987), NSERL Rep. 1. Natl. Soil Erosion Res. Lab., West Lafayette, IN.

Giraldez J.V. and Woolhiser D.A., Analytical integration of the kinematic equation for runoff on a plane under constant rainfall rate and Smith and Parlange infiltration. Water Resou. Res. (1996), 32(11): 3385-3389.

Green W.H., Ampt G.A., Studies of soil physics, I, Flow of air and water through soils, Journal of Agricultural Science (1911), 4:1-24

Henderson F. and Wooding R., Overland flow and groundwater flow from a steady rainfall of finite duration, J. Geophys. Res. (1964), 69 8, pp. 1531-1540.

Horton R.E., The role of infiltration in the hydrologic cycle, (1933) Trans. AGU, 14th Ann. Mtg, 446-460.

Horton R.E., The interpretation ad application of runoff plane experiments with reference to soil erosion problems, Soil Sci. Soc. Am. Proc. (1938), 1, 401-437.

Izzard C.F., The surface profile of overland flow. Trans. Amer. Geophys. Un., 25, 959-968.

Lighthill M.J., Whitham G.B., On kinematic waves. I. Flood movement in long rivers, Proc. R. Soc. London, Ser. A (1955), 229, 281-316.

Liu J., Zhang J. and Feng J., Green-Ampt model for layered 
soils with non uniform initial water content under unsteady infiltration (2008), Soil Sci Soc Am J 72: 10411047.

Luce C.H., Cundy T.W., Modification of the kinematic wave-Philip infiltration overland flow model, Water. Resour. Res. (1992), 28, 1179-1186.

Mizumura K., Analytical solution of nonlinear kinematic wave model, J. of Hydr. Eng, ASCE (2006), 11:6,539546.

Ponce V.M., Cordero-Brana O.I., Hasenin S.Y., Generalized conceptual modeling of dimentionless overland flow hydrographs, J. Hydrol., (1997), 200:222-227.

Risse L.M., Nearing M.A., Savabi M.R., Determining the Green and Ampt effective hydraulic conductivity from rainfall-runoff data for the WEPP mode, (1994), Transactions of the Am. Soc. Agric. Eng. 37:411-418.

Robinson J.S., Sivapalan M., Instantaneous response functions of overland flow and subsurface stormflow for catchment models, Hydrol. Processes (1996), 10, 845-862.

Robinson J.S., Sivapalan M., Snell J.D., On the relative roles of hillslope processes, channel routing, and network geomorphology in the hydrologic response of natural catchment, Wat. Resour. Res. (1995), 31, 12, 3089-3101.

Smith R.E., Keith R.J., Smettem, Philip Broadbridge and David A. Woolhiser, Infiltration Theory for Hydrologic Applications, Water Resources Monograph Series, Vol. 15 (2002), 210 pages, softbound AGU.

Smith R.E., Goodrich D.C., Rainfall excess overland flow, (2005), Encyclopedia of Hydrological Science, Edited by M G Anderson John Wiley \& Sons, Ltd.

Smith R.E., Parlange J.Y., A parameter-efficient hydrologic infiltration model, Water Resour. Res. (1978), 14, 533538.

White I., Sully M.J., Macroscopic and microscopic capillary length and time scales from field infiltration, Water Resou. Res. (1987), 23:1514-1522.

Woolhiser D.A., Liggett J.V., Unsteady one-dimensional flow over a plane-the rising hydrograph. Water Resou. Res. (1967), 3(3): 753-771.

Woolhiser D.A., Smith R.E. and Giraldez J.V., Effect of spatial variability of saturated hydraulic conductivity on Hortonian overland flow. Water Resou. Res. (1996), 32(3): 671-678.

\section{SUMMARY}

This paper deals with the analytical solution of kinematic wave equations for overland flow occurring in an infiltrating hillslope. The infiltration process is described by the Green-Ampt model. The solution is derived only for the case of an intermediate flow regime between laminar and turbulent ones. A transitional regime can be considered a reliable flow condition when, to the laminar overland flow, is also associated the effect of the additional resistance due to raindrop impact.

With reference to the simple case of an impervious hillslope, a comparison was carried out between the present solution and the non-linear storage model. Some applications of the present solution were performed to investigate the effect of main parameter variability on the hillslope response. Particularly, the effect of hillslope geometry and rainfall intensity on the time to equilibrium is shown.
Keywords: hydrologic response, infiltration, analytical solution, kinematic wave equations.

\section{List of simbols}

$f \quad$ infiltration capacity

infiltration capacity at the end of the rainfall $\left[L T^{-1}\right]$

$f_{z w}$ infiltration capacity at the zero water depth $\left[L T^{-1}\right]$

$f_{0} \quad$ infiltration capacity at the time $t_{0} \quad\left[L T^{-1}\right]$

$g$ acceleration due to gravity $\left[L T^{-2}\right]$

$h$ water depth [L]

$h_{*} \quad$ water depth at the time $t_{r}$ at the position $x_{*} \quad[L]$

$i$ rainfall intensity $\left[L T^{-1}\right]$

$k_{*}$ geometry parameter of the hillslope $\quad\left[L^{-2 / 3} T^{-1}\right]$

$K_{i}$ hydraulic conductivity corresponding to the antecedent soil moisture condition $\quad\left[L T^{-1}\right]$

$K_{s} \quad$ saturated hydraulic conductivity $\quad\left[L T^{-1}\right]$

$L$ length of the hillslope [L]

$m$ exponent of water depth in the Manning equation

$n$ Manning friction factor $\quad\left[L^{-1 / 3} T\right]$

$q$ specific discharge $\quad\left[L T^{-1}\right]$

$q^{*} \quad$ normalized specific discharge

$r$ rainfall excess [ $\left.L T^{-1}\right]$

$r_{*} \quad$ rainfall excess normalised with respect to rainfall intensity

$r_{\infty}$ asymptotic value of the rainfall excess [ $\left.L T^{-1}\right]$

$S_{0}$ bed slope

$S_{f}$ friction slope

$t$ time

$t_{c}$ sorptivity time scale [L]

$t_{e q}{ }^{(S M)}$ time to equilibrium according to the non-linear storage model

$t_{e q}$ time to equilibrium according to the kinematic wave model with no infiltration

$t_{k} \quad$ time to equilibrium according to the kinematic wave model with infiltration $\quad[T]$

$t_{p}$ time to ponding [T]

$\begin{array}{cll}t_{r} & \text { duration of rainfall } \\ t_{0} & \text { [T] }\end{array}$

$t_{0}$ time at which characteristic starts from the top of the hillslope

$t^{*} \quad$ normalized time

$u$ flow velocity

$x \quad$ downslope position from the top of the hillslope

$x_{z w}$ position at the condition of zero water depth

$x_{*}$ position corresponding to water depth $h_{*}$ at the time $t_{r}[L]$

$x_{0}$ distance from the top of the hillslope [L]

$\alpha$ correcting factor of the asymptotic time to equilibrium for the non-linear storage model

$\alpha_{*} \quad$ Value of $\alpha$ for which $t_{e q}$ is equal to $t_{e q}{ }^{(S M)}$

$\lambda_{c}$ macroscopic capillary length scale

$\theta$ volumetric water content

$\theta_{c} \quad$ volumetric water content at the field capacity

$\theta_{i} \quad$ initial volumetric water content

$\theta_{r} \quad$ residual volumetric water content

$\theta_{s} \quad$ saturated volumetric water content $\left[L^{3} L^{-3}\right]$

$\rho$ rainfall intensity normalised with respect to saturated hydraulic conductivity

$\psi$ matric potential

$\psi_{b} \quad$ matric potential at the wetting front

$\Psi$ dimensionless function of $\left(i, f, K_{s}\right)$

$\Psi_{0}$ dimensionless function of $\left(f_{0}, f, K_{s}\right)$

$\Psi_{r}$ dimensionless function of $\left(f_{r}, f, K_{s}\right)$

$\Psi_{z w}^{r}$ dimensionless function of $\left(f_{r}, f_{z w}, K_{s}\right)$ 